\title{
EMPIRICAL MODELLING OF A NEAR-TRAFFIC EMISSION HOTSPOT - ANALYSIS OF IMMISSION REDUCTION POTENTIALS
}

\author{
TIM STEINHAUS, MORITZ HARTWIG \& CHRISTIAN BEIDL \\ Institute for Internal Combustion Engines and Powertrain Systems, Technical University of Darmstadt, Germany
}

\begin{abstract}
Two of the greatest challenges for future individual mobility are urban air quality and climate protection. Although a steady reduction of pollutant emissions from motor vehicles has been achieved in the past, local pollution levels within cities still reach levels that are considered hazardous to health. Although the significant contribution of road traffic to total pollution is known, especially at traffic hotspots, modelling the exact interactions remains a challenge. In this paper, a novel approach for the determination of the emission-immission interaction on the basis of a neural network model for the $\mathrm{NO}_{2}$ immission at a near-traffic hotspot scenario is presented. In addition to a detailed description of the modelling procedure, significance analysis of the influencing variables and the interactions considered, it is also described how the specific emissions for the entire vehicle fleet are implemented in accordance with different emission standards under real driving conditions. On the basis of the model presented, achievable immission levels for currently available and future technology are investigated within scenario analysis. Results show that concentrations of less than half of today's yearly average limit values are technically feasible in hotspot situations.

Keywords: air pollution, emission-immission-interaction, recurrent neural networks, $\mathrm{NO}_{2}, \mathrm{NO}_{x}$
\end{abstract}

\section{INTRODUCTION}

The release of substances hazardous to the environment and human health into the ambient air is a process that has accompanied anthropogenic activities for a long time. The impact of a certain concentration of pollutants over time on humans and nature is referred to as immission. From a medical perspective, it is widespread consensus that air pollution can harm human health across the entire lifespan [1], [2], [3], [4], [5]. Because of its ubiquity, individuals generally have little opportunity to avoid exposure. This distinguishes air pollution substantially from other causes of adverse health effects. In the past, increased knowledge about the effects on human health as well as the quantifiable, negative consequences for the environment led to the introduction of air pollution control measures, some of which are also subject to the precautionary principle. The focus of these measures lies primarily on urban air quality. Here, significant improvements have been achieved through the introduction of air quality standards in recent decades [6], [7]. Although the majority of measuring stations comply with the applicable limit values, local exceedances of nitrogen dioxide $\left(\mathrm{NO}_{2}\right)$ and particulate matter are still observed. This is mostly the case in specific, local situations with high traffic volumes, so-called hotspots [8], [9]. Despite the high importance of the influence of vehicle emissions, the description of the exact interaction to the resulting immission is still not fully described and subject of ongoing research. As a result, vehicle emission standards are defined on the basis of technical feasibility rather than on the basis of their attributable immission contribution. Similarly, air pollution control measures are seldom based on quantified action assessments but rather on general assumptions, which are attributed to reduction potentials [10]. Based on an empirical model, this paper presents an approach to quantify the relationship between fleet emission and the corresponding immission impact of a certain 
vehicle fleet. This is done using the example of a hotspot measuring station in Darmstadt, Germany, which has repeatedly exceeded the legal limit values in the past for the species of $\mathrm{NO}_{2}$. Based on this model, targeted changes of the vehicle fleet and the resulting impact on the prevailing immission will be investigated.

\section{METHODOLOGY}

The following explanations are based on the fundamental assumption that the measured variable of interest, the traffic influence, can be isolated as far as possible at an observation location in order to be able to model it as accurately as possible. This assumption is most likely to apply in a situation close to traffic. Here, it can be assumed that the pollution above the prevailing city background is primarily attributable to traffic, with a proportion of the city background immission also being attributable to traffic emissions. By means of the associated emission at a near traffic location, the interaction with the immission can be described according to Fig. 1:

The traffic emissions result from the total vehicle fleet and its associated, type-specific emissions. In order to represent the locally specific fleet, the data are aggregated, which can also include special measures such as vehicle ban or speed restriction scenarios. Resulting fleeting emissions contribute to the prevailing immission value, which is further influenced, in the case of the city background by other, non-traffic emissions. The evaluation of an immission assessment in the context of different scenarios according to the calculation based on Fig. 1 comprises the following three main tasks.

1. Fleet emission calculation

2. Immission calculation

3. Scenario analysis

In the context of this paper, the approach described is applied to an exemplary, representative scenario of a hot-spot measuring point for the pollutant $\mathrm{NO}_{2}$ in close proximity to traffic. The main steps of the procedure and their implementation are described in the following sections.

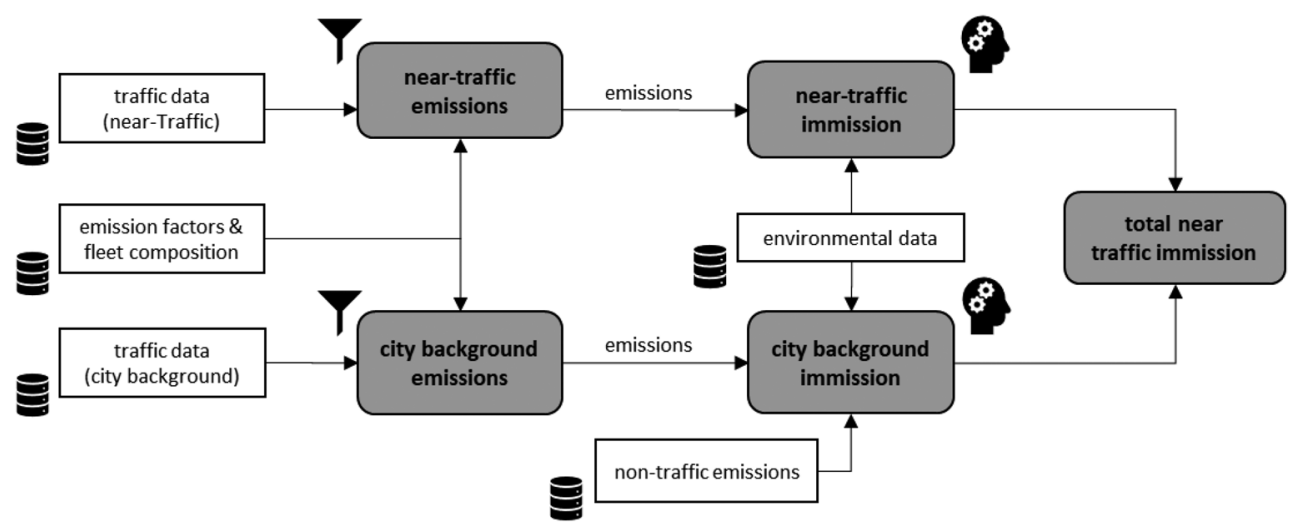

Figure 1: Interaction of emission and immission in the presented model framework. 


\section{IMPLEMENTATION}

As already shown throughout various work such as [5], [7], [10] the problem of inner-city air quality is highly related to traffic-intense areas for the species $\mathrm{NO}_{2}$ and particulates, for which vehicle emissions are primarily held responsible. The application of the outlined approach is particularly suitable due to the relevance of these species in corresponding scenarios. In the following, the characteristics of the chosen use case, as well as the details of the emissions and immission calculation, are presented. This serves as the basis for scenario analyses.

\subsection{Use case}

The proposed modeling method is carried out for the Darmstadt Hügelstraße scenario. This is a near-traffic air quality surveillance station in the city of Darmstadt, Germany, which complies with the requirements of Directive 2018/50/EC and which has regularly exceeded the legal limit values for $\mathrm{NO}_{2}$ in the past as shown in Fig. 2.

As at many other sites with recurring violations of legal limits, the scenario is characterized by dense building development (street canyon) on a main road in the city centre. Local peculiarities are the prevailing one-way street situation and a tunnel exit, which is located $200 \mathrm{~m}$ in front of the measuring station in the direction of travel. Furthermore, special measures were implemented in the past: since 2017, the speed limit is reduced to $30 \mathrm{~km} / \mathrm{h}$ and, as of 1 June 2019, vehicles with emission standard EU5/V for diesel and EU2 for gasoline are restricted in this street [11] - measures that potentially influence the prevailing immission. Thus, the scenario appears to be particularly suitable for empirical modelling, as the changing input variables can become part of the model training and thus an extended range of validity can be covered. A recent assessment of air quality surveillance station positions concludes that only a few measuring stations in inner-city areas close to traffic are representative of the location with the highest concentrations, which is why the highest values may not be recorded [10]. These are particularly present in the area of street canyons. Exactly such a highly polluted situation exists in the case of Darmstadt Hügelstraße, which is the reason why this scenario is highly suitable for investigating most critical conditions. Furthermore, data on influencing parameters as well as on the prevailing background immission in the city and the surrounding area are available. The associated air quality surveillance station for the rural background is located approximately $30 \mathrm{~km}$ outside the city between crop fields.

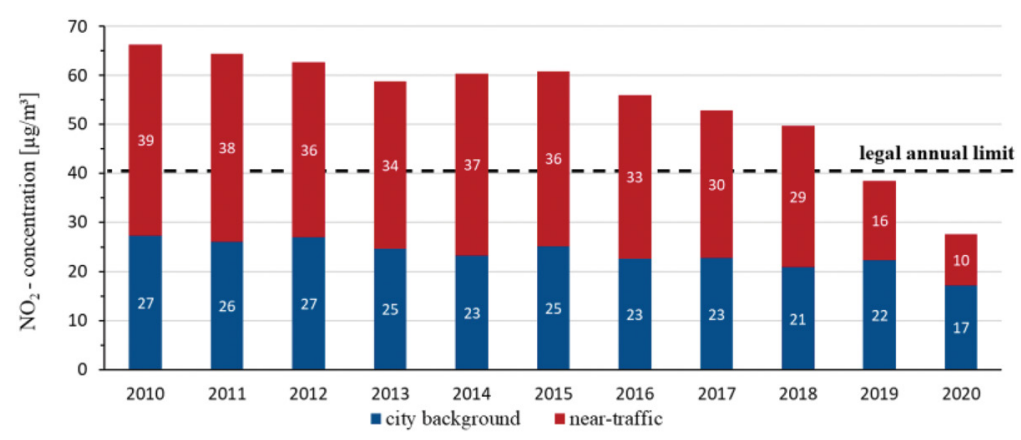

Figure 2: $\mathrm{NO}_{2}$ immission trend (yearly averages) for the chosen near-traffic scenario Darmstadt Hügelstraße, separated into city background (blue) and near-traffic (red) share. 
Table 1: Input parameters of the empirical model for near-traffic (NT) and city background (CB) $\mathrm{NO}_{2}$-immission with data sources.

\begin{tabular}{|c|c|c|}
\hline \multirow[b]{2}{*}{ Input parameters } & \multicolumn{2}{|c|}{ Modelled site } \\
\hline & Near traffic & City background \\
\hline Ambient pressure $^{1}$ & $\mathrm{X}$ & $\bar{X}$ \\
\hline Ambient temperature $^{1}$ & $\mathrm{X}$ & $\mathrm{X}$ \\
\hline Ambient humidity ${ }^{1}$ & $\mathrm{X}$ & $\mathrm{X}$ \\
\hline NOx fleet emission (NT) & $\mathrm{X}$ & \\
\hline NOx fleet emission (CB) & & $\mathrm{X}$ \\
\hline $\mathrm{NO}_{2} / \mathrm{NO}_{\mathrm{x}}$ emission ratio $(\mathrm{NT})$ & $\mathrm{X}$ & \\
\hline $\mathrm{NO}_{2} / \mathrm{NO}_{\mathrm{x}}$ emission ratio (CB) & & $\mathrm{X}$ \\
\hline Ozone concentration ${ }^{1}$ & $\mathrm{X}$ & $\mathrm{X}$ \\
\hline Residential energy consumtion ${ }^{2}$ & & $\mathrm{X}$ \\
\hline Solar radiation ${ }^{1}$ & $\mathrm{X}$ & $\mathrm{X}$ \\
\hline Wind speed ${ }^{1}$ & $\mathrm{X}$ & $\mathrm{X}$ \\
\hline Wind direction ${ }^{1}$ & $\mathrm{X}$ & $\mathrm{X}$ \\
\hline
\end{tabular}

${ }^{1}$ HLNUG [12], ${ }^{2}$ SMARD [13].

Given this situation, it is possible to carry out the proposed modelling of the additional trafficrelated pollution separately from the prevailing city background. In order to achieve a high model quality, it is indispensable to represent the essential influencing parameters of the model. For this purpose, the data of these parameters have to be available, both for training and later use. The scenario was also chosen on the basis of this prerequisite, since a good coverage of the influencing variables with a high temporal resolution is guaranteed. The available data of the respective measuring station are listed in Table 1.

\subsection{Fleet emission calculation}

The quantification of fleet emissions assumes that the sum of all traffic emissions in the comparison period is decisive for the measured immission load. The emissions differ depending on the type of vehicle, the emission standard as well as the traffic and environmental situation in which it is currently located. For specific specifications of these parameters, an individual emission factor (EFA) can be specified for each vehicle class. The fleet emission is then calculated as

$$
E F A_{\text {total }}=\sum_{i} E F A_{i} \cdot n_{i}
$$

In this context, $i$ describes the vehicle category, $E F A_{\mathrm{i}}$ its emission factor and $n_{\mathrm{i}}$ the number of vehicles of the respective category. This relation emphasizes that a low number of vehicles with a high emission factor has the same influence on the immission load as a high number of vehicles with correspondingly low emission factors. The EFAs are obtained from 
the Handbook of Emission Factors (HBEFA) version 4.1, as is the fleet composition. HBEFA is a database that makes it possible to determine corresponding average emissions of the vehicle fleet for adjustable traffic situations and definable boundary conditions. The stored emissions are based on the Passenger Car and Heavy-Duty Model (PHEM). This model is used to determine emissions for the representative traffic situations. The model reproduces the essential emission formation mechanisms as well as the exhaust gas after-treatment reactions for vehicle classes. Ageing effects are also considered herein. The calibration of the models is based not only on the measurements of the Federal Environmental Offices such as Germany, Austria or Switzerland but also other test and analysis facilities, both in Real Driving Emission Tests and in classical test bench measurements. [14], [15]

Altogether, the authors assume that the used HBEFA data resemble real-life emissions over the entire vehicle life cycle with sufficient accuracy and representation for the real emission situation. In all following steps, the specific EFAs and vehicle category shares are considered constant for every year.

\subsection{Immission calculation}

With the available data on known influencing parameters to ambient air pollution, an empirical modelling approach is pursued instead of a physical dispersion model. While physical models also provide robust results and are frequently used for air control plans, their associated modelling effort is comparatively high. Furthermore, deviations also remain here due to inaccurate or non-existent physical representation of certain transformation processes. The determination of the EFAs on the basis of the models stored in HBEFA might itself be subject to inaccuracies. Empirical modelling offers the possibility that such errors in the input data are compensated for by the correlations stored in the model, which arise during training. This is impossible with physical modelling. [16], [17], [18]

Regardless of the modelling type, it is necessary that the prevailing mechanisms can be replicated. In the case of an empirical modelling approach, the necessary influencing parameters driving these reactions must be specified. Vehicles with internal combustion engines emit primary, i.e. direct, $\mathrm{NO}_{2}$. Similarly, secondary $\mathrm{NO}_{2}$ emissions arise from the atmospheric conversion of directly emitted NO according to the reactions in formulae 1,2 and 3. The secondary formation mechanism usually outweighs the primary pathway [19].

$$
\begin{gathered}
2 \mathrm{NO}+\mathrm{O}_{2} \rightarrow 2 \mathrm{NO}_{2} \\
\mathrm{NO}+\mathrm{O}_{3} \rightarrow \mathrm{NO}_{2}+\mathrm{O}_{2} \\
\mathrm{NO}+\text { peroxideradicals } \rightarrow \mathrm{NO}_{2}+\text { radicals }
\end{gathered}
$$

Likewise, a reverse reaction is also effective, which leads to the conversion of $\mathrm{NO}_{2}$ to ozone and NO through solar radiation:

$$
\mathrm{NO}_{2}+\mathrm{O}_{2}+\text { solar radiation } \rightarrow \mathrm{NO}+\mathrm{O}_{3}
$$


The significance of oxygen and ozone for the reaction chemistry of $\mathrm{NO}$ and $\mathrm{NO}_{2}$ can be deduced from the preceding reaction equations, the conversion mechanism of which takes place according to formula 5 .

$$
\mathrm{O}+\mathrm{O}_{2} \rightarrow \mathrm{O}_{3}
$$

These are only the most significant equations; in fact, many more exist, especially for the reactants of $\mathrm{NO}_{2}$ mentioned here. For calculations of the special case on the transformation of $\mathrm{NO}_{2}$ in street canyons, the gas chemistry of the troposphere is reduced to reaction equations 2, 3 and 5. This approach is based on the assumption that other reactions take place much more slowly and that the current concentration is dominated by the reactions mentioned [20].

Besides the complex, physical-chemical mechanisms, the emitted components are diluted within the ambient air. In the case of vehicles as emitters, the immission concentration attributable to traffic thus depends on the parameters that influence the chemical reactions in the ambient air described above. Underlying are numerous environmental conditions such as ambient temperature, humidity, wind direction, wind speed, air pressure, solar radiation, the local building situation and the distance between the emission and immission measuring point. According to the empirical modelling approaches, these influencing parameters are used to determine the immission load. A neural network is used here, which calculates non-linear relationships by means of adaptive, neuro-fuzzy interference systems. The overall interaction is described by separation into subproblems and approximating these using polynomial functions. The model generation can be controlled e.g. by parameters for adapting the polynomial functions or weighting individual sub-models. To store the effective relationships, the model is calibrated with existing input and output data of the system during a training phase. In the specific application, this is done using measurement data from five consecutive years (2015-2019). The input and output parameters of the generated models of the near-traffic and city background immission are listed in Table 1. For the training phase, the response quantity $\left(\mathrm{NO}_{2}\right.$ immission) has to be available as input data as well.

The result is a compiled model, which calculates the resulting immission on the basis of influencing ambient boundary conditions and traffic emissions for every $30 \mathrm{~min}$ sample. The temporal resolution of the model can be classified as high. In this way, the model is trained for a very wide range of prevailing conditions. For instance, there is comparatively low traffic at night with correspondingly low emissions - a situation that is of general importance for the representation of low fleet emissions. Similarly, the back and forth reaction of $\mathrm{NO}_{2}$ (formulas 2-4 versus 5) changes during the course of the day, which can also be resembled within the neuronal structures of the model due to its high temporal resolution. And, of course, the quality of the representation of fast changes in influencing variables is also favoured by a high temporal resolution; for example, increasing and decreasing traffic volumes at rush hour or, depending on the season of the year, fast changes in temperature after sunrise or sunset. All in all, the authors assume that a high temporal resolution should have beneficial effects on accuracy, both in terms of correctness and precision.

The modelling approach is applied for the immission calculation at two measurement sites: the near-traffic scenario Darmstadt Hügelstraße and the corresponding city background measurement station. By means of the separate calculation of the city background, the influence of traffic on the prevailing immission level of the city besides near-traffic areas is considered. Both models are validated on the basis of the goodness of fit to existing measurement data. This includes both the training period and the non-training period. The latter aspect is 
particularly important, as it is possible that the model will only deliver reliable results within the trained range due to overfitting.

\section{RESULTS}

Within this section, results of the proposed immission model are presented. To ensure the quality of the modelling procedure, statistical parameters and comparisons between modelled and measured immission are first discussed. Subsequently, the models are used to investigate the effects of changes in the vehicle fleet on the prevailing load at the hotspot in scenario by varying the emissions of the vehicle fleet.

\subsection{Influence and quality analysis}

The general influence of the transmission reaction by the parameters presented above (see Table 2) is well known. However, the exact magnitude and relationship between the influencing variables for the specific object of interest is unclear. For this reason, a correlation analysis is carried out in order to quantify the correlations between the influencing variables and the residual emission balancing. In addition to the significance of a parameter for the prevailing immission, the comparison of the influencing variables with each other is also of interest. Besides drawing conclusions for model training settings, this work also serves to deepen the understanding of the system. Both Pearson and Spearman correlation coefficients of input parameters are investigated. As they provided consistent results, only Pearson correlation coefficient are discussed in the following. According to expectations, the prevailing immission at the near-traffic hotspot is strongly influenced by the prevailing $\mathrm{NO}_{\mathrm{x}}$ fleet emission, with a clearly positive, linear correlation at $r_{\mathrm{No}_{2}, \mathrm{No}_{x}}=0.62$. For the city background, there is also a positive correlation $\left(r_{\mathrm{No}_{2}, \mathrm{No}_{\mathrm{X}}}=0.17\right)$ to traffic emissions, although it is significantly lower than in close proximity to the street.

Table 2: Correlation matrix of immission and environmental influencing parameters for the near-traffic scenario Darmstadt Hügelstraße.

\begin{tabular}{|c|c|c|c|c|c|c|c|c|}
\hline & 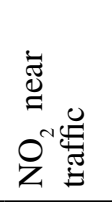 & 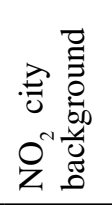 & 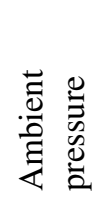 & 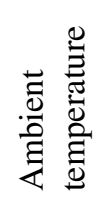 & $\begin{array}{l}\vec{d} \\
\mathbb{D} \\
\end{array}$ & 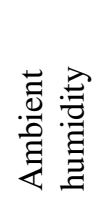 & 疍 & 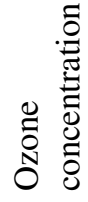 \\
\hline $\mathrm{NO}_{2}$ near traffic & 1 & & & & & & & \\
\hline $\mathrm{NO}_{2}$ city background & 0.26 & 1 & & & & & & \\
\hline Ambient pressure & 0.13 & 0.19 & 1 & & & & & \\
\hline Ambient temperature & 0.32 & -0.38 & -0.09 & 1 & & & & \\
\hline Wind speed & -0.07 & -0.36 & -0.17 & 0.01 & 1 & & & \\
\hline Ambient humidity & -0.46 & 0.33 & -0.03 & -0.62 & -0.35 & 1 & & \\
\hline Solar radiation & 0.41 & -0.31 & 0.06 & 0.57 & 0.23 & -0.65 & 1 & \\
\hline Ozone concentration & 0.28 & -0.60 & 0.18 & 0.71 & 0.35 & -0.76 & 0.57 & 1 \\
\hline
\end{tabular}


Among the influencing environmental parameters listed in Table 2, highest sensitivities of the emission are observed for solar radiation and ozone concentration - strong indications of the already mentioned sensitivity of the transformation processes to intermediate products (ozone) and its driving mechanisms (energy input through solar radiation). The correlation to air humidity, which can also be understood as rain in a broader sense, is equally striking. Measurement data show sharp decreases in the prevailing $\mathrm{NO}_{2}$ immission in the event of rain. Furthermore, strong seasonal differences are observed for temperature, average wind speed, humidity, ozone concentration and solar radiation. The authors conclude that this is presumably the reason for negative correlation among these parameters.

With regard to the additional emission input for the city background, an up-to-date data source that provides direct residual emissions within the city area could not be identified. However, it is expected that non-traffic emissions are linked to energy consumption. Correlation analysis results in a positive interaction coefficient of 0.48 between residential electrical energy consumption and immission concentration in the near-traffic scenario. For the urban background immission, the correlation is significantly weaker at 0.24 , remaining positive. One reason can be found in the likewise persisting correlation between traffic volume and electricity consumption, which is a result of the corresponding periods of anthropogenic activity.

Furthermore, it is analysed whether the considered variables are subject to a possible temporal offset, as this applies to effective reactions. It is questionable to what extent this has to be considered in the usage of measurement data. For this reason, an additional cross-correlation analysis is carried out. Since it is assumed that a potential temporal offset is not subject to major fluctuations over long time periods, data from 21 February 2018 to 4 March 2018 is examined in this regard. The highest cross-correlation result is obtained for no time shift for the near-traffic immission calculation $(\mathrm{lag}=0)$ and one measurement sample $(\mathrm{lag}=1$ resp. 30 $\mathrm{min}$ ) in the case of the city background, which is probably due to the greater distance of the probe position from the road. However, the difference between the cross-correlation for lag $=1$ and lag $=0$ is not significant $(p=0.008)$. Consideration of the shift in the models would, therefore, not be justified. Overall, there are no indications that would support the assumption of delayed impact mechanisms over several hours based on the conducted analysis.

\subsection{Immission modelling}

Based on the previous observations, the neural network structure is trained with the input variables according to Table 1 . A variation is carried out to determine the optimal control parameters of the model. The highest model quality according to the statistical parameters listed in Table 3 is obtained for the local approximation by means of fourth-order polynomial functions per layer. A small layer overlap was selected, which favours a higher model quality but can also tend to lead to more discontinuous behaviour.

Furthermore, an increase in dispersion is observed for higher immission concentrations. This effect is stronger for the city background. Compared to the statistical parameters of a linear regression analysis, the model quality could be increased considerably - the coefficient of determination $R^{2}$ increases from 0.634 to 0.867 in the near-traffic and urban background from 0.547 to 0.817 . Higher model quality can be achieved in training with shorter time periods. However, the authors assume that this also increases the risk of unconsidered conditions. Dependencies that are found for a short period of time do not necessarily have to be valid for a longer period of time. In particular, a wide range model validity and extrapolation ability of 
Table 3: Statistical parameters of the model training.

\begin{tabular}{|c|c|c|c|}
\hline & $R^{2}$ & RMSE & NRMSE \\
\hline $\begin{array}{l}y_{i}=\text { measured value } \\
\bar{y}=\text { mean meas. value } \\
\hat{y}=\text { predicted value }\end{array}$ & $1-\frac{\sum}{\sum}$ & $\sqrt{\frac{\sum_{i=1}^{n}\left(y_{i}-\hat{y}_{i}\right)^{2}}{n}}$ & $\frac{R M S E}{\left(y_{\max }-y_{\min }\right)} \cdot 100 \%$ \\
\hline Near-traffic model & 0.867 & 13.026 & $3,933 \%$ \\
\hline City background model & 0.817 & 6,411 & $5,212 \%$ \\
\hline
\end{tabular}

models that have been trained with short data periods is often limited for this reason, despite a higher coefficient of determination. For reasons of robustness, a period of 5 years from 2015 to 2019 is chosen for training. Furthermore, statistical analysis shows that correlations of the near-traffic immission are represented more clearly as the city background. This is probably due to the direct emission influence in close proximity to traffic, while this interaction is less dominant in the city background. Thus, influence of environmental parameters is higher here. It should be noted here that the resolution on very small scales is subject to significant fluctuations. Therefore, assessments of the immission load are rather carried out on larger time scales on a monthly or annual basis, as the long-term trend is of interest regardless of temporary distortions.

Input data for the years 2015-2019 were again used in the final generated models for additional traffic-related pollution and background immission. For result validation, the year 2020 was also included, which was not part of the training. Due to the COVID-19 pandemic during this period, temporary lockdown measures were in force in the scenario under investigation, which significantly affected the vehicle number over a period of approximately 4 weeks in the months of March and April (up to -62\%). For the rest of the year, traffic volumes remained within the expected average of recent years. In order to isolate a potential COVID19 effect on the $\mathrm{NO}_{2}$ immission, traffic data for the year 2020 is corrected by normalization of this period on the basis of the averages from 2015 to 2019.

In the medium-term trend of the $\mathrm{NO}_{2}$-immission load between the years 2015 and 2020, shown in Fig. 3, the simulation results for near traffic deviate on average by $-0.3 \%$ from the measured values. During these 6 years, a tendency for the annual mean values to be underestimated in the period from 2015 to 2017 is followed by slight overestimations in the years 2018 to 2020 . The smallest deviation occurs in 2018 with $0.7 \mu \mathrm{g} / \mathrm{m}^{3}$, the largest in 2020 with $2.6 \mu \mathrm{g} / \mathrm{m}^{3}$. As mentioned, this is the year that, in contrast to the previous years, was not part of the training data set. For the urban background, a higher overall accordance of the modelled annual mean values with the measured data can be observed. This is noteworthy insofar as the associated statistical analysis parameters of the model quality were slightly lower. The mean deviation over the period shown is $0.6 \mu \mathrm{g} / \mathrm{m}^{3} \mathrm{NO}_{2}(2.5 \%)$ and the qualitative replication is also given. A supposed anomaly in the measurement data of the year 2019 is also represented correctly: a predominant immission increase in 2019 despite strongly declining immission at near-traffic area. Apparently, conditions prevailed in 2019 that had a favourable effect on the pollution situation of the measuring point close to the traffic but not on the urban background pollution. Overall, the model quality achieved is in the upper range compared to other empirical, traffic-related immission models and can be classified as high [18], [17]. 


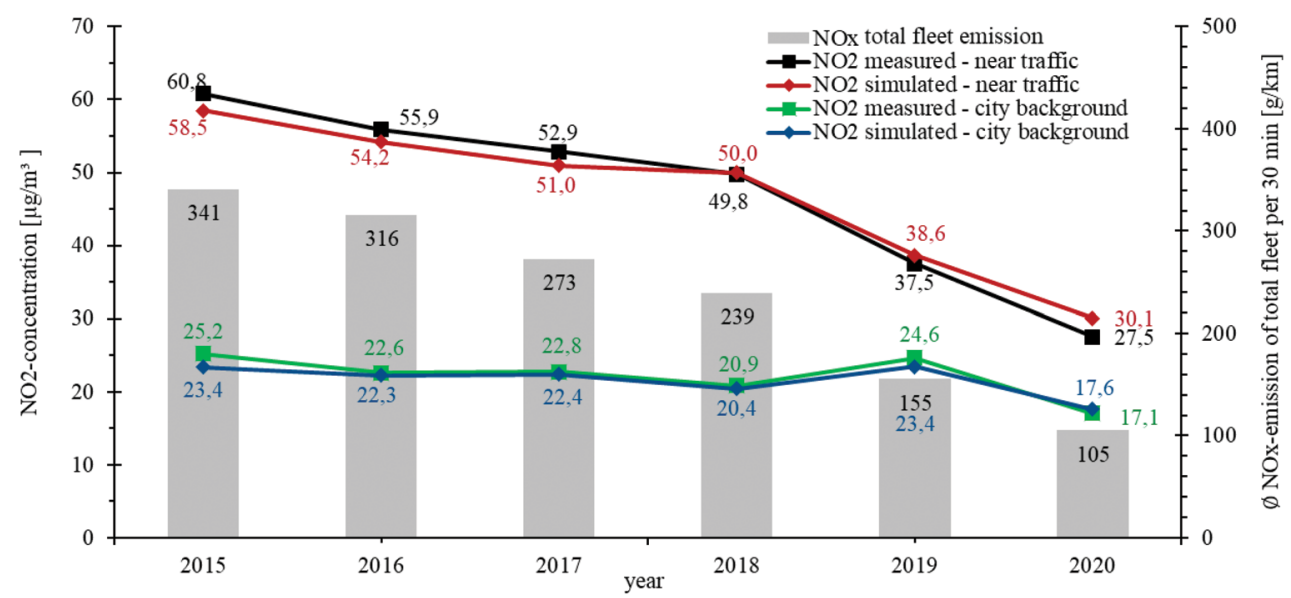

Figure 3: Validation of the derived $\mathrm{NO}_{2}$-emission-immission model - comparison of measurement to simulation for near-traffic (black/red line) and city background (blue/ green line) immission and corresponding near-traffic total fleet $\mathrm{NO}_{\mathrm{x}}$-emission (grey bars).

\subsection{Scenario analysis}

With the previously developed model, projections of the future development of $\mathrm{NO}_{2}$ pollution are derived for the near-traffic scenario. The development of the immission load for the predicted, "natural" change in the vehicle fleet composition within the next 10 years is taken as baseline case. It is then compared to different boundary condition scenarios by varying the vehicle fleet emissions calculating resulting immission loads. For this purpose, the ambient conditions from the reference year 2020 are kept constant. The vehicle fleet category composition in the near-traffic scenario consists of $92.3 \%$ of the passenger car vehicles (PCV), $3.7 \%$ of type light duty vehicle (LDV), $2.4 \%$ of type heavy duty vehicle (HDV), $1.4 \%$ of type motorcycle and $0.2 \%$ of the type bus. Changes within the vehicle fleet are represented by specific emission vectors calculated for the respective fleet composition and its associated emission factors. The immission model thus receives scenario-specific parameters as input variables for which a corresponding immission is calculated. On this basis, the future compliance to immission limits is assessed. Furthermore, isolated immission contributions for different vehicle emission standards can be quantified by the boundary consideration of a complete fleet penetration.

According to the change of the vehicle fleet composition by HBEFA for the years up to 2030, the development of total fleet emission for the near-traffic scenario Darmstadt Hügelstraße, as depicted in Fig. 4, is overall reduced by $-51.3 \%$. The largest share remains for PCVs, although they account for the majority of the decline. With $92 \%$ of the total vehicle number, they emit $51 \%$ of total traffic $\mathrm{NO}_{x}$ by 2030 . Conversely, the $2.4 \%$ of trucks emit $44 \%$ of all $\mathrm{NO}_{x}$. Compared to the development of fleet emissions over the past 6 years (see Fig. 3), the dynamic of the annual relative emission reduction decreases, with the $\mathrm{NO}_{\mathrm{x}}$-fleet emission in 2030 being $15 \%$ of that in 2015 .

The impact of this fleet development on the immission situation, shown in Fig. 5, is twofold: a significant decrease of $19.9 \%$ up to 2030 is observed in the near-traffic area, while the 


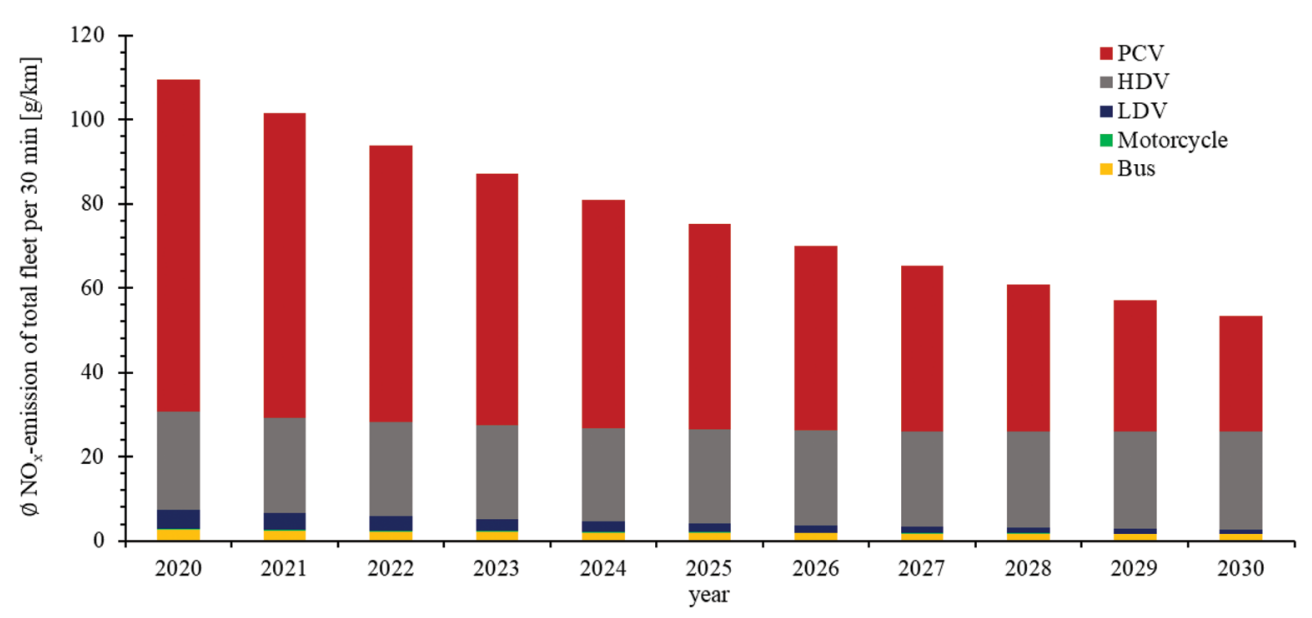

Figure 4: Near-traffic emission trend allocated to vehicle categories up to the year 2030.

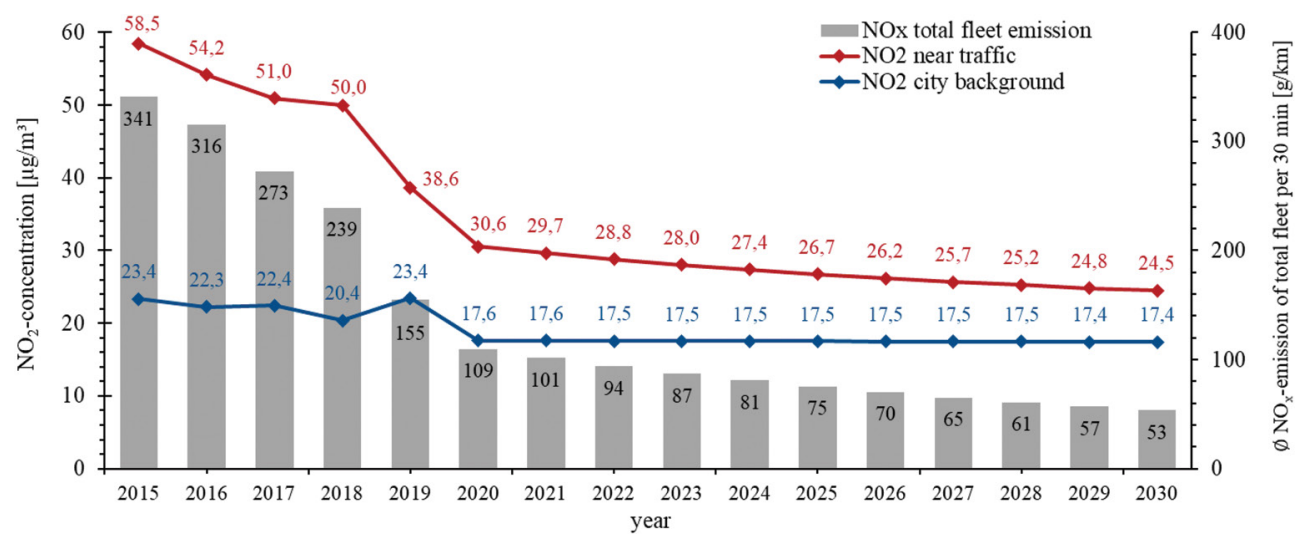

Figure 5: $\mathrm{NO}_{2}$ immission trend for near traffic (red) and city background (blue) based on expected replacement of vehicle fleet.

city background hardly reacts to the emission reduction $(-1.1 \%)$. However, the decrease of the immission's near-traffic share (total near-traffic - total city background) with $7.1 \mu \mathrm{g} / \mathrm{m}^{3}$ from $13.0 \mu \mathrm{g} / \mathrm{m}^{3}$ corresponds in its magnitude to that of the $\mathrm{NO}_{\mathrm{x}}$ fleet emissions $(-45.4 \%)$.

As seen in previous years, emission reductions have a significantly weaker effect on the city background than on near traffic. In combination with the decreasing reduction dynamics of the emissions, the slight decrease can be explained. Deviations result, among other factors, from the ozone concentration assumed to be constant for years after 2020. An analysis in this respect shows that an increase in the $\mathrm{O}_{3}$ concentration equivalent to that of the long-term average $\left(-69 \% \mathrm{NO}_{\mathrm{x}} \rightarrow+10 \% \mathrm{O}_{3}\right)$ leads to a slight decrease in the calculated $\mathrm{NO}_{2}$ immission (NT: $-0.1 \%, \mathrm{CB}:-3.1 \%)$. Thus, the present overestimation of the model lies within the error tolerance (compared to Table 3 ) and is thus to be classified as non-significant. 


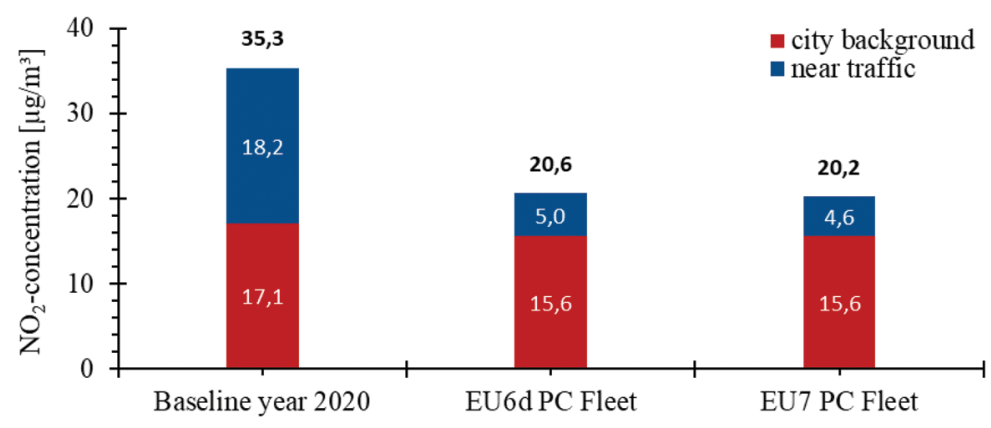

Figure 6: $\mathrm{NO}_{2}$-immission potential for emission standards with total fleet substitution for passenger cars in the hotspot scenario Darmstadt Hügelstraße.

At $17.4 \mu \mathrm{g} / \mathrm{m}^{3}$, the city background immission is only $3.6 \mu \mathrm{g} / \mathrm{m}^{3}(25.7 \%)$ above the rural background of $13.8 \mu \mathrm{g} / \mathrm{m}^{3}$ in the reference year 2020. Accordingly, a reduced emission results in only a limited reduction potential for the city background immission. Extrapolated to zero traffic emissions, the remaining city background immission is $14.9 \mu \mathrm{g} / \mathrm{m}^{3} \mathrm{NO}_{2}$. Overall, in this scenario of a hotspot, the total immission load approaches the value of $20 \mu \mathrm{g} / \mathrm{m}^{3}$, which was named as a potential future limit value [3]. With new emission standards currently being discussed, it is of interest how these affect the near-traffic immission concentrations. Here, too, the model offers the possibility of quantifying the influence of present and new emission standards on air quality as depicted in Fig. 6.

Same as for the EU6d emissions, the emission factors for a potential successive emission standard (EU7) are also derived from HBEFA 4.1. Compared to the previously discussed immission load in the case of natural fleet renewal by 2030, a further reduction potential of $3.9 \mu \mathrm{g} / \mathrm{m}^{3}$ remains in the case of complete fleet penetration by EU6d emission standard for PCV. In contrast, EU7 would hardly result in further reduction of the prevailing $\mathrm{NO}_{2}$ concentration in the near-traffic scenario, although the emissions in the passenger car category would approximately be cut to half according to HBEFA. The underlying reason is the now strong influence of HDV: Although they have only a very small share in urban traffic, high emitter influence becomes very significant. It should be noted, however, that reductions of HDV and other categories emissions, apart from PCV, were not considered due to data availability.

\section{CONCLUSION}

In order to ensure the lowest possible immission, it is of interest to be able to model the effects of main emitters such as vehicles with internal combustion engines particularly well. In this way, it is possible to precisely quantify their influence on the immission situation and to estimate future developments in a substantiated manner. The presented approach for empirical immission simulation by means of neural networks and the application to a trafficrelated hotspot scenario for the species $\mathrm{NO}_{2}$ delivers high-quality results and is, therefore, used for an immission assessment.

It is shown that in recent years there has been a strong decrease in traffic emissions, which is also noticeable in the immission. As a result, limit value exceedances are only to be expected in exceptional cases. As a result of further fleet penetration of newer vehicles with $\mathrm{NO}_{\mathrm{x}}$ emissions that are lower under real operating conditions, the downward trend will continue. The 
technical limit potential of the current EU6d passenger car fleet reduces the current prevailing emission of the year 2020 (COVID-19 effects excluded) by $42 \%$ to $20.6 \mu \mathrm{g} / \mathrm{m}^{3}$ and thus half of the currently valid limit value. Such a continued reduction through future emission standards is not to be expected, as the absolute level of emissions has already fallen very sharply and the remaining reduction potential is therefore very small.

\section{ACKNOWLEDGEMENTS}

The authors would like to thank the Hessisches Landesamt für Naturschutz, Umwelt und Geologie (HLNUG) and the city of Darmstadt for their cooperation, provision of measurement data and the professional exchange.

\section{REFERENCES}

[1] World Health Organization. Health Risks of Air Pollution in Europe - HRAPIE project. Recommendations for Concentration-Response Functions for Cost-Benefit Analysis of Particulate Matter, Ozone and Nitrogen Dioxide. WHO Regional Office for Europe, Kopenhagen, 2013.

[2] Ritz, B., B. Hoffmann und A. Peters. The effects of fine dust, ozone, and nitrogen dioxide on health. Deutsches Arzteblatt International, 116(51-52), 881-886, 2019. DOI: 10.3238/arztebl.2019.0881.

[3] Héroux, M.-E., et al. Quantifying the health impacts of ambient air pollutants: recommendations of a WHO/Europe project. International Journal of Public Health, 60(5), 619-627, 2015. DOI: 10.1007/s00038-015-0690-y.

[4] Brunekreef, B. Health effects of air pollution observed in cohort studies in Europe. Journal of Exposure Science \& Environmental Epidemiology, 17(Suppl 2), S61-5, 2007. DOI: 10.1038/sj.jes.7500628.

[5] Cyrys, J., et al. Variation of $\mathrm{NO}_{2}$ and $\mathrm{NO}_{x}$ concentrations between and within 36 European study areas: results from the ESCAPE study. Atmospheric Environment, 62, 374-390, 2012. DOI: 10.1016/j.atmosenv.2012.07.080.

[6] Nagl, C., W. Spangl und I. Buxbaum. Sampling Points for Air Quality. Policy Department for Economic, Scientific and Quality of Life Policies, Luxembourg, 2019.

[7] European Environment Agency. Air Quality in Europe. 2019 Report. Luxembourg: Publications Office of the European Union, 2019. EEA report. No 10/2019. ISBN 9789294800886.

[8] World Health Organization. WHO Air Quality Guidelines for Particulate Matter, Ozone, Nitrogen Dioxide and Sulfur Dioxide. Global update 2005. Summary of Risk Assessment. World Health Organization, Genf, 2005.

[9] Raaschou-Nielsen, O., et al. Traffic air pollution and mortality from cardiovascular disease and all causes: a Danish cohort study. Environmental Health, 11, 60, 2012. DOI: 10.1186/1476-069X-11-60.

[10] Nagl, C., et al. Air Quality and Urban Traffic in the EU: Best Practises and Possible Solutions. Policy Department for Citizens' Rights and Constitutional Affairs, Brussels, 2018.

[11] Verwaltungsgericht Wiesbaden. Vergleichsvereinbarung im Verwaltungsstreitverfahren Verkehrsclub Deutschland e.V. und Deutsche Umwelthilfe e.V. ./. Land Hessen, 12 December 2018 [Press release]. Available at: https://www.duh.de/fileadmin/user_ upload/download/Projektinformation/Verkehr/Luftreinhaltung/Vergleich_VCDDUH_ LdHessen_LRP_Darmstadt.pdf (accessed 5 May 2021). 
[12] Hessisches Landesamt für Naturschutz, Umwelt und Geologie. Luftmessstelle Darmstadt [online]. Available at: https://www.hlnug.de/messwerte/datenportal/ messstelle/2/1/0104/ (accessed 6 May 2021).

[13] Bundesnetzagentur. SMARD - Strommarktdaten [online]. Marktdaten, 2021. Available at: https://www.smard.de/home/downloadcenter/download-marktdaten (accessed 6 May 2021).

[14] Matzer, C., Weller K., Dippold M., Lipp S., Röck M., Rexeis M. und S. Hausberger. Update of Emission Factors for HBEFA Version 4.1. Final report. I-05/19/CM EM-I16/26/679, 9. Sep. 2019.

[15] Keller, M., et al. HBEFA Version 3.3. Hintergrundbericht. INFRAS, Bern, 2017.

[16] Chen, J., et al. A comparison of linear regression, regularization, and machine learning algorithms to develop Europe-wide spatial models of fine particles and nitrogen dioxide. Environment International, 130, 104934, 2019. DOI: 10.1016/j.envint.2019.104934.

[17] Kohoutek, S. Quantifizierung der Wirkungen des Straßenverkehrs auf Partikel-und Stickoxid-Immissionen. Dissertation, Technische Universität Darmstadt, Darmstadt, 2011.

[18] Hrust, L., et al. Neural network forecasting of air pollutants hourly concentrations using optimised temporal averages of meteorological variables and pollutant concentrations. Atmospheric Environment, 43(35), 5588-5596, 2009. DOI: 10.1016/j. atmosenv.2009.07.048.

[19] Baumbach, G. Luftreinhaltung. Entstehung, Ausbreitung und Wirkung von Luftverunreinigungen - Meßtechnik, Emissionsminderung und Vorschriften. Dritte Auflage. Springer: Berlin, Heidelberg, 1994. ISBN 3540568239.

[20] Neunhauserer, L., et al. Stand der Modellierungstechnik zur Prognose der NO2Konzentrationen in Luftreinhalteplänen nach der 39. BImSchV. Bundesumweltamt, Dessau-Roslau, 2011. 